\title{
Inhalation Therapy for Stable COPD: 20 Years of GOLD Reports
}

Paul D. Terry · Rajiv Dhand

\section{ABSTRACT}

The Global Initiative for Chronic Obstructive Lung Disease (GOLD) was formed in the late 1990s to spread awareness of chronic obstructive pulmonary disease (COPD) as a major public health problem and facilitate its prevention and treatment. GOLD has since become internationally recognized for the development of evidence-based strategy documents, most notably the annual GOLD Reports, for COPD diagnosis, management, and prevention. The GOLD Reports incorporate the latest evidence

Enhanced Digital Features To view enhanced digital features for this article go to https://doi.org/10.6084/ m9.figshare.11940423.

P. D. Terry · R. Dhand $(\bowtie)$

Department of Medicine, Graduate School of Medicine, University of Tennessee Medical Center, Knoxville, TN, USA

e-mail: rdhand@utmck.edu; rdhand@uthsc.edu and expert consensus to guide the management and prevention of COPD on a global level. Since the first GOLD Report in 2001, profound innovations have taken place regarding inhaler device options, available pharmaceuticals, knowledge regarding effective dosages and potential side effects, and the various combinations of drugs used to relieve symptoms. Concomitantly, an evolution of expert opinion on how best to apply these innovations to the care of patients with COPD has also taken place, an evolution that is nowhere more detailed or definitive than in the 20 years of annual GOLD Reports. We summarize key features and trends in inhalation therapy for stable COPD in these Reports.

Keywords: COPD; GOLD reports; Inhalation therapy 


\section{Key Summary Points}

The Global Initiative for Chronic Obstructive Lung Disease (GOLD) is internationally recognized for the development of evidence-based strategy documents, most notably the annual GOLD Reports

The GOLD Reports incorporate the latest evidence and expert consensus to guide the management and prevention of COPD on a global level

The 20 years during which GOLD published their annual Reports has been a period of remarkable innovation and refinement of inhalation therapy for COPD

The GOLD Reports document profound evolutions in the armamentarium of inhaled drugs in all categories of inhalation devices; the use of long-acting, combination, and triple therapies; algorithms for initial and follow-up treatment; the acceptance of nebulizers in regular maintenance therapy; and the emphasis on inhalation device choice, technique, and adherence, all of which are designed to optimize outcomes in COPD management

We summarize key features and trends in inhalation therapy for stable COPD in these Reports

\section{INTRODUCTION}

The GOLD Expert Panel, a distinguished group of health professionals from the fields of respiratory medicine, epidemiology, socioeconomics, public health, and health education, reviewed existing COPD guidelines, as well as new information on pathogenic mechanisms of COPD as they developed a consensus document. Many recommendations will require additional study and evaluation as the GOLD program is implemented.

-Claude Lenfant, MD, Director, National

Heart, Lung, and Blood Institute,1982-2003 [1].

The Global Initiative for Chronic Obstructive Lung Disease (GOLD) has its origins as a National Heart, Lung, and Blood Institute- and World Health Organization-sponsored "think tank," formed in the late 1990s to spread awareness of chronic obstructive pulmonary disease (COPD) as a major public health problem and facilitate its prevention and treatment [2]. GOLD has since become internationally recognized for the development of evidencebased strategy documents, most notably the annual GOLD Reports, for COPD diagnosis, management, and prevention. The GOLD Reports incorporate the latest evidence and expert consensus to guide the management and prevention of COPD on a global level [3].

The first annual GOLD Report, Global Strategy for Diagnosis, Management and Prevention of COPD was issued in 2001. The GOLD Science Committee, comprising recognized leaders in COPD research and clinical practice, was established shortly thereafter to review published research findings and evaluate their impact on recommendations in the subsequent GOLD documents. The evaluation of science and methodology behind each of the annual Gold Report revisions involves, at a minimum, review and discussion of literature twice a year by the Science Committee, as well as rewriting and updating content as it relates to the literature review. There was no annual Report issued by GOLD in 2002 or 2012. Thus, the most recent GOLD Report, for 2020, made available in December 2019 (https:// goldcopd.org), marks the 18th report to have contributed substantially towards meeting GOLD's founding goals “to increase awareness of COPD and help the thousands of patients who suffer from this disease and die prematurely from COPD or its complications [2]."

Patients with COPD rely heavily on inhaled bronchodilators and inhaled corticosteroids (ICS) to control symptoms, maximize their quality of life, and avoid exacerbations and 
costly hospitalizations. Since the first GOLD Report in 2001, profound innovations have taken place regarding inhaler device options, available pharmaceuticals, knowledge regarding effective dosages and potential side effects, and the various combinations of drugs used to relieve symptoms. Concomitantly, an evolution of expert opinion on how best to apply these innovations to the care of patients with COPD has also taken place, an evolution that is nowhere more detailed or definitive than in the 20 years of annual GOLD Reports.

Oral therapies considered in the GOLD Reports include methylxanthines (aminophylline, theophylline), phosphodiesterase 4 inhibitors (roflumilast), and mucolytic agents (erdosteine, carbocysteine, $\mathrm{N}$-acetylcysteine). Our focus is on inhaled therapies, however, which are faster in onset than oral therapies, have less side effects, are more commonly used, and are often considered more effective in the long-term management of symptoms in patients with stable COPD.

Our aim here is not to distill GOLD's treatment recommendations for clinical use. Rather, because the collective GOLD Reports provide context and perspective on the ever-expanding treatment choices facing patients and their providers, we summarize key features and trends in inhalation therapy for stable COPD in these Reports. This article is based on previously conducted studies and does not contain any studies with human participants or animals performed by any of the authors.

\section{A NOTE ON METHODS AND THE GOLD REPORTS FORMAT}

\section{Relevant Chapters}

The first GOLD Report (2001) comprised six chapters: (1) Definition; (2) Burden of COPD; (3) Risk Factors; (4) Pathogenesis, Pathology and Pathophysiology; (5) Management of COPD; and (6) Future Directions. Chapter 5, Management of COPD, comprised four components: (1) Assess and Monitor Disease; (2) Reduce Risk Factors; (3) Manage Stable COPD; and (4) Manage Exacerbations. In this report, our primary focus is on the pharmacological treatments discussed in the third component of this chapter: "Manage Stable COPD." In 2011, a new chapter, "Therapeutic Options," was added, which then contained the specific information on pharmacological therapies; the chapter was retitled "Evidence Supporting Prevention and Maintenance Therapy" in 2017.

\section{Levels of Evidence}

At various places in each Report, the GOLD Science Committee qualifies the level of evidence supporting COPD management recommendations hierarchically from " $\mathrm{A}$ " (highest) to " $\mathrm{D}$ " (lowest). We refer to these levels of evidence when highlighting certain GOLD recommendations in our discussion. Levels of evidence are defined by GOLD on the basis of the following data sources:

A Large, well-designed randomized controlled trials (RCTs) with no perceived important source of bias

B RCTs with limited numbers of patients, limited duration of follow-up, limited consistency of study results, and/or with perceived methodological weaknesses

C Non-randomized trials and observational studies

D Panel consensus judgment based on clinical experience or knowledge that does not meet the above criteria; the available clinical literature is insufficient

\section{COPD Severity of Airflow Limitation and Pharmacological Management Classifications}

The first GOLD Report (2001) used the following severity of airflow designation for patients with COPD based on spirometric assessment: 0 . At Risk; (1) Mild; (2) Moderate; (3) Severe. In 2003, a fourth category was added: (4) Very Severe. In 2006, the category "At Risk" was no longer used. The four remaining categories have been used in GOLD Reports through 2020. In the 2011 Report, GOLD stated: "In previous versions of the GOLD Report, COPD treatment 
recommendations were based on spirometry only. This is in keeping with the fact that most of the clinical trial evidence about treatment efficacy in COPD is oriented around baseline $\mathrm{FEV}_{1}$ (forced expiratory volume in one second). However, $\mathrm{FEV}_{1}$ alone is a poor descriptor of disease status and for this reason the treatment strategy for stable COPD should also consider an individual patient's symptoms and future risk of exacerbations." With this, GOLD presented a new model for the initiation of pharmacological management of COPD according to both the spirometric classification and the individualized assessment of symptoms and exacerbation risk:

Group A Less symptoms, low risk

Group B More symptoms, low risk

Group C Less symptoms, high risk

Group D More symptoms, high risk

A refined version of the ABCD Assessment Tool is presented in the GOLD 2020 Report (Fig. 1).

\section{Formulations and Typical Doses of COPD Medications}

A table in the 2001 GOLD Report "Commonly Used Formulations of Bronchodilator Drugs" listed the generic drug name, the inhaler typeor nebulizer-used to deliver the drug, the common dose or dose range for each, and the expected duration of action. A footnote to the table noted that not all formulations and doses are available or typical in all countries. This table exists in all GOLD Reports to date, albeit with modifications within each of the categories over time in accordance with the available scientific evidence. In 2010, the title of the table changed to "Formulations and Typical Doses of COPD Medications," and in 2017 to "Commonly Used Maintenance Medications in COPD." Starting in 2019, typical doses of listed drugs were no longer provided. Whereas we selectively cite information from these tables in our discussion, we do not reiterate GOLD's justification for including or excluding specific drugs (Tables 1, 2, 3, 4).

\section{INHALED PHARMACOLOGICAL THERAPY IN GOLD}

\author{
Inhaled Bronchodilators
}

Inhaled bronchodilators are central to symptom management and commonly given on a regular basis to prevent or reduce symptoms. Bronchodilators act by altering airway smooth muscle tone and the improvements in expiratory flow reflect widening of the airways rather than changes in lung elastic recoil. Bronchodilators tend to reduce dynamic hyperinflation at rest and during exercise and improve exercise performance.

-GOLD Report, 2020

As noted by GOLD, inhaled bronchodilators are used to prevent and control symptoms, reduce the frequency and severity of exacerbations, improve health status, and improve exercise tolerance. GOLD Reports consistently note, however, that no drug or combination of drugs has been shown conclusively to decrease the rate of patients' long-term decline in lung function. The 2009 and 2010 GOLD Reports noted limited evidence (Evidence B) that regular treatment with long-acting $\beta_{2}$-agonists (LABAs), inhaled corticosteroids (ICS), and/or their combination can decrease the rate of decline of lung function. However, subsequent evidence has not supported this suggestion and the association was not noted in subsequent Reports. The most recent GOLD Report (GOLD, 2020), however, cites evidence to suggest that triple inhaled therapy, specifically triple combinations of a LABA, a long-acting muscarinic antagonist (LAMA), and an ICS, may reduce mortality among patients with the most severe stages of COPD (see "Triple Therapy").

Discussion of inhaled bronchodilators is found in all GOLD Reports under four main headings: $\beta_{2}$-Agonists; Anticholinergics (or Antimuscarinics or Muscarinic antagonists); Inhaled corticosteroids; and Combination bronchodilator therapy. We address each of these four treatment categories below, focusing more on drug effectiveness than side effects. 


\section{THE REFINED ABCD ASSESSMENT TOOL}
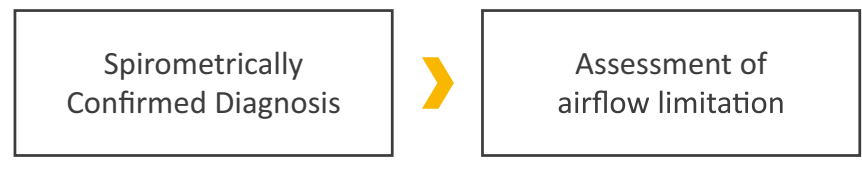

Assessment of symptoms/risk of exacerbations

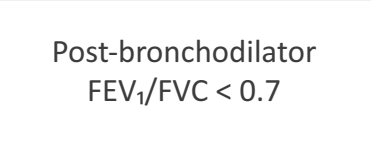

\begin{tabular}{|l|l|}
\hline Grade & \multicolumn{1}{c|}{$\begin{array}{c}\text { FEV }_{1} \\
\text { (\% predicted) }\end{array}$} \\
\hline GOLD 1 & $\geq 80$ \\
\hline GOLD 2 & $50-79$ \\
\hline GOLD 3 & $30-49$ \\
\hline GOLD 4 & $<30$ \\
\hline
\end{tabular}

Moderate or Severe Exacerbation History
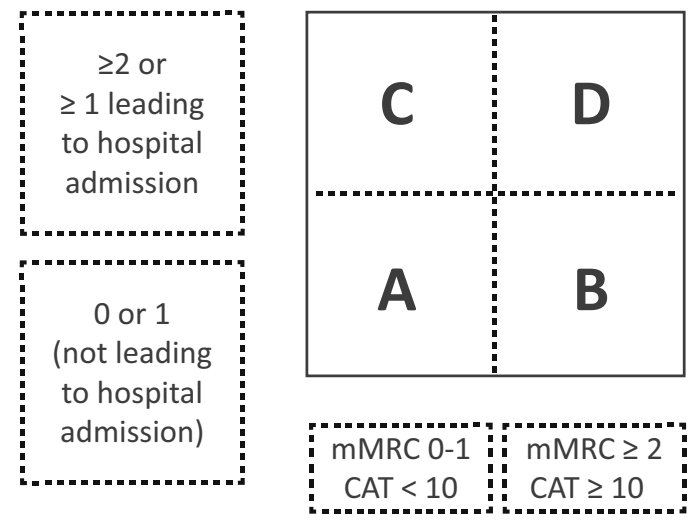

Symptoms

FIGURE 2.4

Fig. 1 The refined $A B C D$ assessment tool

\section{$\beta_{2}$-Agonists}

The principal action of beta2-agonists is to relax airway smooth muscle by stimulating beta2-adrenergic receptors, which increases cyclic AMP and produces functional antagonism to bronchoconstriction. There are short-acting (SABA) and long-acting (LABA) beta2-agonists. The effect of SABAs usually wears off within 4 to $6 \mathrm{~h}$.

-GOLD Report, 2020

The first GOLD Report (2001) listed five $\beta_{2}$ agonists (in the table "Commonly Used Formulations of Bronchodilator Drugs"): SABAs fenoterol, albuterol, terbutaline, and LABAs formoterol, and salmeterol (Table 1). Typical doses for pressurized metered-dose inhaler (pMDI)-delivered and nebulizer-delivered drugs were provided; dry powder inhaler (DPI)-specific dose information was added in 2003. Henceforth divided under "short-acting" and "long-acting" headings, this list grew to include SABA levalbuterol (2007), and LABAs arformoterol (2009), indacaterol (2010), vilanterol (2014, in combination with umeclidinium), and olodaterol (2016). Changes in the typical doses of these drugs occurred over successive reports, including the discontinuation of nebulized terbutaline after 2001 and pMDI-delivered formoterol after 2016.

\section{Anticholinergics/Antimuscarinics/ Muscarinic Antagonists}

Antimuscarinic drugs block the bronchoconstrictor effects of acetylcholine on M3 muscarinic receptors expressed in 
Table $1 \beta_{2}$-Agonists devices and doses for treating patients with stable COPD in the GOLD Reports, 2001-2020

\begin{tabular}{|c|c|c|c|}
\hline$\beta_{2}$-Agonists & Inhaler $(\mu \mathrm{g})$ & $\begin{array}{l}\text { Solution for nebulizer (mg/ } \\
\mathrm{ml} \text { ) }\end{array}$ & Duration of action $(h)$ \\
\hline \multicolumn{4}{|l|}{ Short acting ${ }^{\mathrm{a}, \mathrm{b}}$} \\
\hline Fenoterol & 100-200 (pMDI) & $0.5-2.0$ to $1^{\mathrm{c}}$ & $4-6$ \\
\hline $\begin{array}{l}\text { Albuterol } \\
\text { (salbutamol) }\end{array}$ & 100-200 (pMDI and DPI) & $2.5-5.0$ to $5^{\mathrm{d}}$ & $4-6$ \\
\hline Terbutaline & $250-500$ to $400-500^{\mathrm{e}}$ (DPI) & $5-10^{f}$ & $4-6$ \\
\hline Levalbuterol $^{\mathrm{g}}$ & $45-90(\mathrm{pMDI})$ & $0.6,1.25$ to $0.21,0.42^{\mathrm{g}}$ & $6-8$ \\
\hline \multicolumn{4}{|l|}{ Long acting ${ }^{\mathrm{a}, \mathrm{b}}$} \\
\hline Formoterol & $12-24$ to $4.5-12^{\mathrm{h}}(\mathrm{pMDI} \text { and DPI })^{\mathrm{i}}$ & & 12 \\
\hline Salmeterol & $50-100$ to $25-50^{j}$ (pMDI and DPI) & & 12 \\
\hline Arformoterol $^{\mathrm{k}}$ & & 0.0075 & 12 \\
\hline Indacaterol $^{1}$ & $150-300$ to $75-300(\mathrm{DPI})^{\mathrm{m}}$ & & 24 \\
\hline Olodaterol $^{\mathrm{n}}$ & $5(\mathrm{SMI})$ & & 24 \\
\hline
\end{tabular}

Specific doses were no longer shown in "Commonly Used Maintenance Medications in COPD" after 2018

a Short- vs. long-acting formulations were separated into categories in 2003

b DPI-specific dose information was added in 2003; the 2001 Report listed pMDI doses only

c Nebulized solution dose for fenoterol changed from $0.5-2.0$ to $1 \mathrm{mg} / \mathrm{ml}$ in 2003

${ }^{d}$ Nebulized solution dose for albuterol changed from $2.5-5.0$ to $5 \mathrm{mg} / \mathrm{ml}$ in 2003

e pMDI dose for terbutaline changed from $250-500 \mu \mathrm{g}$ to $400-500 \mu \mathrm{g}$ in 2003

${ }^{\mathrm{f}}$ Nebulized solution of terbutaline was discontinued after 2001

g Nebulized solution of levalbuterol was added in 2007 and changed from 0.63 or 1.25 to 0.21 or $0.42 \mathrm{mg} / \mathrm{ml}$; levalbutrol pMDI was added in 2008

${ }_{\mathrm{h}}$ pMDI dose for formoterol changed from $12-24 \mu \mathrm{g}$ to $4.5-12 \mu \mathrm{g}$ (pMDI and DPI) in 2003

i pMDI formulation of formoterol was discontinued after 2016; DPI dose changed to 4.5-9 $\mu \mathrm{g}$ in 2017

${ }^{j}$ pMDI dose for salmeterol changed from $50-100 \mu \mathrm{g}$ to $25-50 \mu \mathrm{g}$ in 2003

k Arformoterol was added in 2008

${ }^{1}$ Indacaterol was added in 2010

${ }^{m}$ DPI dose of Indacaterol was changed in 2011 to $75-300 \mu \mathrm{g}$

${ }^{\mathrm{n}}$ Olodaterol was added in 2016

airway smooth muscle. Short-acting antimuscarinics (SAMAs), namely ipratropium and oxitropium, also block the inhibitory neuronal receptor $\mathrm{M} 2$, which potentially can cause vagally induced bronchoconstriction. Long-acting muscarinic antagonists (LAMAs), such as tiotropium, aclidinium, glycopyrronium bromide and umeclidinium have prolonged binding to M3 muscarinic receptors, with faster dissociation from M2 muscarinic receptors, thus prolonging the duration of bronchodilator effect.

-GOLD Report, 2020

The initial GOLD Report (2001) listed two anticholinergics in common use at that time, both short-acting: ipratropium bromide and oxitropium bromide (Table 2). These two drugs remain the only SAMAs listed in the 2020 Report. Several LAMAs were subsequently added: tiotropium in 2003; aclidinium bromide and glycopyrronium bromide in 2013; umeclidinium in 
Table 2 Anticholinergics, devices, and doses for treating patients with stable COPD in the GOLD Reports, 2001-2020

\begin{tabular}{|c|c|c|c|}
\hline Anticholinergics & Inhaler $(\mu \mathrm{g})$ & Solution for nebulizer $(\mathrm{mg} / \mathrm{ml})$ & Duration of action $(h)$ \\
\hline \multicolumn{4}{|l|}{ Short acting, } \\
\hline Ipratropium bromide & $40-80$ to $20,40^{\mathrm{c}}$ (pMDI) & $0.25-0.5$ & $6-8$ \\
\hline Oxitropium bromide & 200 to $100^{\mathrm{d}}$ (pMDI) & $1.5^{\mathrm{e}}$ & $7-9$ \\
\hline \multicolumn{4}{|l|}{ Long acting ${ }^{a}$} \\
\hline \multirow[t]{3}{*}{ Tiotropium $^{\mathrm{f}}$} & 18 (DPI) & & 24 \\
\hline & $5(\mathrm{SMI})^{\mathrm{g}}$ & & 24 \\
\hline & pMDI & & \\
\hline Aclidinium bromide ${ }^{\mathrm{h}}$ & 322 to 400 DPI, 400 pMDI $^{\mathrm{i}}$ & & 12 \\
\hline Glycopyrronium bromide $^{j}$ & 44 (DPI) & & 24 to $12-24^{\mathrm{k}}$ \\
\hline Umeclidinium $^{1}$ & 62.5 (DPI) & & 24 \\
\hline Glycopyrrolate $^{\mathrm{m}}$ & & & 12 \\
\hline Revefenacin $^{\mathrm{n}}$ & & & 24 \\
\hline
\end{tabular}

Specific doses were no longer shown in “Commonly Used Maintenance Medications in COPD” after 2018

a Short- vs. long-acting formulations were separated into categories in 2003

b DPI-specific dose information was added in 2003; the 2001 Report listed pMDI doses only

c Ipratropium dose changed from $40-80$ to 20 or $40 \mu \mathrm{g}$ in 2003

d Oxitropium dose changed from 200 to $100 \mu \mathrm{g}$ in 2003

e Oxitropium solution for nebulizer was added in 2003; it was discontinued in 2017

$\mathrm{f}$ Tiotropium was added in 2003; pMDI formulation was added in 2020

g Soft mist inhaler (SMI) formulation for tiotropium was added in 2009

${ }^{\mathrm{h}}$ Aclidinium bromide was added in 2013

${ }^{\text {i }}$ Aclidinium dose (DPI) changed from 322 to $400 \mu \mathrm{g}$ in 2017; pMDI dose of $400 \mu \mathrm{g}$ was added in 2017

j Glycopyrronium bromide was added in 2013

k Glycopyrronium dose was changed to 15.6 and $50 \mu \mathrm{g}$ (DPI) and duration of action was changed from 24 to $12-24 \mathrm{~h}$ in 2017

${ }^{1}$ Umeclidinium was added in 2015

${ }^{\mathrm{m}}$ Glycopyrrolate was added in 2020 as a nebulizer solution

${ }^{\mathrm{n}}$ Revefenacin was added in 2020 as a nebulizer solution

2016; glycopyrrolate and revefenacin in 2020. Other changes over time include those related to specific doses of drugs, and additions and discontinuations of a delivery device for a specific drug, such as the addition (2003) and subsequent discontinuation (2017) of a nebulized solution of oxitropium bromide.

\section{Inhaled Corticosteroids (ICS)}

In vitro evidence suggests that COPD-associated inflammation has limited responsiveness to corticosteroids. Moreover, some drugs including $\beta_{2}$-agonists... may partially facilitate corticosteroid sensitivity in COPD. The clinical relevance of this effect has not yet been fully established.

-GOLD Report, 2020

In 2001, GOLD suggested that regular treatment with ICS was only appropriate for symptomatic patients with COPD and a documented spirometric response to ICS. In 2003, this statement was clarified to exclude all but 
Table 3 Inhaled corticosteroids, devices, and doses for treating patients with stable COPD in the GOLD Reports, 2001-2020

\begin{tabular}{lll}
\hline $\mathbf{I C S}^{\mathbf{a}}$ & Inhaler $(\boldsymbol{\mu g})$ & Solution for nebulizer $(\mathbf{m g} / \mathbf{m l})$ \\
\hline Beclomethasone & $50-400(\mathrm{pMDI}$ and DPI) & $0.2-0.4$ \\
Budesonide & $100,200,400(\mathrm{DPI})$ & $0.20,0.25,0.5$ \\
Fluticasone & $50-500(\mathrm{pMDI}$ and DPI) \\
Triamcinolone ${ }^{\mathrm{b}}$ & $100(\mathrm{pMDI})$ & 40 \\
\hline${ }^{\mathrm{a}}$ Inhaled corticosteroids were only listed in combination with other drugs after 2016 (see Table 4) \\
$\mathrm{b}$ Triamcinolone was discontinued after 2009
\end{tabular}

symptomatic patients with COPD and an $\mathrm{FEV}_{1}$ of less than $50 \%$ predicted and repeated exacerbations (Evidence A). The 2003 Report also noted the results of a few studies suggesting that regular treatment with ICS reduces all-cause mortality. As mentioned earlier, later GOLD Reports did not find sufficient evidence to clearly support this hypothesis.

The initial GOLD Report (2001) listed four ICS as potential treatments for patients with stable COPD: Beclomethasone, Budesonide, Fluticasone, Triamcinolone (Table 3). Fluticasone was discontinued after 2006. Later GOLD Reports noted that ICS are less effective alone than in combination with a LABA in improving lung function and health status in patients with exacerbations and moderate to very severe COPD (Evidence A). It was also noted that most studies found that regular treatment with ICS alone did not modify long-term decline of $\mathrm{FEV}_{1}$ or mortality in patients with COPD. The 2011 Report stated, "Long-term monotherapy with inhaled corticosteroids is not recommended in COPD because it is less effective than the combination of inhaled corticosteroids with LABAs (Evidence A)." After 2016, ICS were listed in "Commonly Used Maintenance Medications in COPD" only in combination with drugs of other classes; ICS as a discrete therapy was no longer listed. Notwithstanding, the 2019 Report noted the results of a study that found fluticasone furoate alone was associated with slower decline in $\mathrm{FEV}_{1}$ compared with placebo or vilanterol alone in moderate COPD.
Effect Modification by Blood Eosinophil Level In 2017, GOLD noted that high blood eosinophil levels may be a useful biomarker to predict efficacy of ICS, and hence inform treatment decisions. The Report cited evidence that showed a reduction of exacerbations from a LABA/ICS combination versus only a LABA or only a LAMA was greater in patients with higher blood eosinophil counts; however, further evidence was needed. By 2019, GOLD noted additional evidence that blood eosinophil counts predict the magnitude of the effect of ICS, added on top of regular maintenance bronchodilator treatment, in preventing future exacerbations. GOLD further noted: "There is a continuous relationship between blood eosinophil counts and ICS effects; no and/or small effects are observed at lower eosinophil counts, with incrementally increasing effects observed at higher eosinophil counts. Data modelling indicates that ICS-containing regimens have little or no effect at a blood eosinophil count $<100$ cells $/ \mu \mathrm{L}$, therefore this threshold can be used to identify patients with a low likelihood of treatment benefit with ICS. The threshold of a blood eosinophil count $>300$ cells $/ \mu \mathrm{L}$ identifies the top of the continuous relationship between eosinophils and ICS, and can be used to identify patients with the greatest likelihood of treatment benefit with ICS." However, by 2020, GOLD still cautioned that: "There is insufficient evidence to recommend that blood eosinophils should be used to predict future exacerbation risk on an individual basis in COPD patients." 
Table 4 Drug combinations, devices, and doses for treating patients with stable COPD in the GOLD Reports, 2001-2020

\begin{tabular}{llll}
\hline Drug & Inhaler $(\mu \mathrm{g})$ & $\begin{array}{l}\text { Solution for nebulizer } \\
(\mathrm{mg} / \mathrm{ml})\end{array}$ & $\begin{array}{l}\text { Duration of action } \\
(\mathrm{h})\end{array}$
\end{tabular}

Combination short-acting $\beta_{2}$-agonists plus anticholinergic in one inhaler

$\begin{array}{llll}\text { Fenoterol/ipratropium }^{\mathrm{a}} & 200 / 80(\mathrm{pMDI}) & 1.25 / 0.5 \mathrm{in} 4 \mathrm{ml} & 6-8 \\ \text { Albuterol/ipratropium }^{\mathrm{a}} & 75 / 15(\mathrm{pMDI})^{\mathrm{b}} & 0.75 / 4.5 \text { to } 0.5,2.5{\text { in } 3 \mathrm{ml}^{\mathrm{c}}}^{6-8} & 6-8\end{array}$

Combination long-acting $\beta_{2}$-agonists plus anticholinergic in one inhaler

$\begin{array}{lll}\text { Indacaterol/glycopyrronium }^{\mathrm{e}} & 85 / 43(\mathrm{DPI}) & 24 \\ \text { Vilanterol/umeclidinium }^{\mathrm{f}} & 25 / 62.5(\mathrm{DPI}) & 24 \\ \text { Formoterol/aclidinium }^{\mathrm{g}} & 12 / 340(\mathrm{DPI}) & 12 \\ \text { Olodaterol/tiotropium }^{\mathrm{h}} & 5 / 5(\mathrm{SMI}) & 24 \\ \text { Formoterol/glycopyrronium }^{\mathrm{i}} & 9.6 / 14.4 \text { to } 9.6 / 18 & 12 \\ & (\mathrm{pMDI}) & \\ \text { Formoterol/glycopyrrolate }^{\mathrm{j}} & 4.8 / 9 & 12\end{array}$

Combination long-acting $\beta_{2}$-agonists plus glucocorticosteroids in one inhaler

$\begin{array}{lc}\text { Formoterol/budesonide }^{\mathrm{k}} & 4.5 / 160(\mathrm{pMDI} \\ & 9 / 320(\mathrm{DPI}) \\ \text { Formoterol/mometasone }^{1} & 10 / 200,10 / 400 \\ & (\mathrm{pMDI}) \\ \text { Salmeterol/fluticasone }^{\mathrm{m}} & 50 / 100,250,500 \\ & (\mathrm{DPI}) \\ & 25 / 50,125,250 \\ & (\mathrm{pMDI}) \\ \text { Vilanterol/fluticasone furoate }^{\mathrm{n}} & 25 / 100(\mathrm{DPI}) \\ \text { Formoterol/beclomethasone }^{\mathrm{o}} & 6 / 100(\mathrm{pMDI} \& \mathrm{DPI}) \\ \left.\text { Triple combination in one device }^{(L A B A / L A M A} / \mathrm{ICS}\right)^{\mathrm{p}} \\ \text { Fluticasone/umeclidinium/vilanterol }\end{array}$

(DPI)

Beclometasone/formoterol/glycopyrronium ${ }^{r}$ (pMDI) 
Table 4 continued

\begin{tabular}{llll}
\hline Drug & Inhaler $(\mu \mathrm{g})$ & $\begin{array}{l}\text { Solution for nebulizer } \\
(\mathrm{mg} / \mathrm{ml})\end{array}$ & $\begin{array}{l}\text { Duration of action } \\
(\mathrm{h})\end{array}$ \\
\hline
\end{tabular}

Specific doses were no longer shown in "Commonly Used Maintenance Medications in COPD" after 2018

a Combination added in 2003

${ }^{\mathrm{b}}$ pMDI formulation for albuterol/ipratropium combination was discontinued after 2013

c Albuterol/ipratropium combination solution for nebulizer was changed to $0.75 / 0.5$ in 2010, discontinued in 2013, and added back as $0.5,0.25 \mathrm{mg} / \mathrm{ml}$ in 2017

d A soft mist inhaler (SMI) formulation for albuterol/ipratropium combination $(100 / 20 \mu \mathrm{g})$ was added in 2014

e Indacaterol/glycopyrronium combination was added in 2014

${ }^{\mathrm{f}}$ Vilanterol/umeclidinium combination was added in 2014

${ }^{\mathrm{g}}$ Formoterol/aclidinium combination was added in 2015

${ }^{\text {h }}$ Olodaterol/tiotropium combination was added in 2017

${ }^{\mathrm{i}}$ Formoterol/glycopyrronium combination was added in 2017; dose was changed to $9.6 / 18$ in 2018

j Formoterol/glycopyrrolate combination was added in 2018

${ }^{\mathrm{k}}$ Formoterol/budesonide combination was added in 2003

${ }^{1}$ Formoterol/mometasone combination was added in 2013

m Salmeterol/fluticasone combination was added in 2003

${ }^{n}$ Vilanterol/fluticasone combination was added in 2014

${ }^{\circ}$ Formoterol/beclomethasone combination was added in 2015 for pMDI; DPI formulation was added in 2016

P Triple therapy was added to GOLD's "Commonly Used Maintenance Medications in COPD” table in the 2019 Report

${ }^{\mathrm{q}}$ Fluticasone/umeclidinium/vilanterol combination was added in 2019 (doses and devices were not specified)

${ }^{\mathrm{r}}$ Beclometasone/formoterol/glycopyrronium combination was added in 2019 (doses and devices were not specified)

\section{Effect Modification by Exacerbation History}

A statement that the treatment effect of ICScontaining regimens is higher in patients with high exacerbation risk first appeared in GOLD's 2019 Report, which concluded: "The use of blood eosinophil counts to predict ICS effects should always be combined with clinical assessment of exacerbation risk (as indicated by the previous history of exacerbations)."

\section{Combination Therapy}

Combining bronchodilators with different mechanisms and durations of action may increase the degree of bronchodilation with a lower risk of side effects compared to increasing the dose of a single bronchodilator. -GOLD Report, 2020

Since 2001, several combinations of inhaled drugs used to treat COPD have been added to
GOLD's “Commonly Used Maintenance Medications in COPD" (Table 4). The combinations of drugs listed in the table of each Report are those available in one inhaler device. Not listed in the tables are combinations involving the use of more than one inhaler device. For example, although not listed in the table, the 2017 Report noted that treatment with formoterol and tiotropium (LABA/LAMA) in separate inhalers was shown to have a greater impact on $\mathrm{FEV}_{1}$ than either component alone.

\section{$S A B A / S A M A$}

The first GOLD Report (2001) noted that a combination of a SABA and ipratropium (SAMA) in stable COPD produced greater and more sustained improvements in $\mathrm{FEV}_{1}$ than either drug alone (Evidence A). By 2003, this statement was expanded more generally to SABA/SAMA combinations and by 2011 to also improving symptoms. Combinations of 
fenoterol/ipratropium and albuterol/ipratropium in one inhaler were first listed in the 2003 Report.

\section{SABA/LABA or LAMA}

The 2011 Report noted that regular and asneeded use of SABAs improves FEV F $_{1}$ and symptoms (Evidence B), but that the use of high doses of SABAs on an as-needed basis in patients already treated with long-acting bronchodilators is not supported by evidence and cannot be recommended. However, the 2017 and later Reports state that LABAs do not preclude additional benefit from as-needed SABA therapy.

\section{LABA/LAMA}

As mentioned above, the 2017 Report noted that treatment with formoterol and tiotropium in separate inhalers was shown to have a greater impact on $\mathrm{FEV}_{1}$ than either component alone. The possibility that this LABA/LAMA combination improves lung function more effectively than monotherapy was first noted in the 2011 Report (Evidence B). In 2014, GOLD noted that LABA/LAMA combinations have shown a significant increase in lung function whereas the impact on patient-reported outcomes was still limited. The Report also noted that there was still too little evidence to determine if a combination of long-acting bronchodilators is more effective than a LABA alone for preventing exacerbations. In the 2017 Report, it was more definitively stated that a "combination treatment with a LABA and LAMA increases FEV $_{1}$ and reduces symptoms and exacerbations compared to monotherapy (Evidence A)." The Report also noted that a lower dose, twice daily regimen for a LABA/LAMA was shown to improve symptoms and health status in patients with COPD.

\section{LABA/LAMA by Exacerbation History}

The 2017 Report noted that most studies with LABA/LAMA combinations have been performed in patients with a low rate of exacerbations, but a study in patients with a history of exacerbations found that a combination of long-acting bronchodilators was more effective than long-acting bronchodilator monotherapy for preventing exacerbations. (A similar effect modification by exacerbation history was mentioned earlier for ICS.) Additional evidence regarding effect modification by exacerbation history was available in 2019, when GOLD noted that several (but not all) studies supported greater benefits from LABA/LAMA combinations compared with long-acting bronchodilator monotherapy among patients with a history of exacerbations. Although not specific to exacerbations, the 2018 GOLD Report noted the results of a clinical trial that found LABA/LAMA treatment had the greatest improvement in quality of life, compared with its individual bronchodilator components, in patients with the highest baseline symptom burden.

\section{$L A B A / I C S$}

The GOLD 2017 Report noted beneficial effects of LABA/ICS over LABA alone on exacerbation rate. For patients with persistent dyspnea, exercise limitation, or exacerbations on LABA/ ICS treatment, the Report suggested that a LAMA can be added to escalate to triple therapy. In 2019, GOLD noted that initial therapy with LABA/ICS has the greatest likelihood of reducing exacerbations in patients with blood eosinophil counts of 300 cells $/ \mu \mathrm{L}$ or higher, and perhaps also in patients with both COPD and a history of asthma. The Report further noted that de-escalating from LABA/ICS to LABA/ LAMA should be considered if the original indication for ICS was not appropriate, given the increased risk of side effects with ICS, such as pneumonia.

\section{Triple Therapy}

The 2011 Report first mentioned "triple therapy" when stating that the addition of a LABA/ ICS combination to tiotropium improves lung function and quality of life and may further reduce exacerbations (Evidence B). The Report emphasized that more studies of triple therapy were needed. In the 2013 Report, GOLD recognized that a few patients with newly diagnosed very severe COPD may benefit from triple therapy, and further noted the importance of validating the effects of individual drugs before 
using a combination. Most of the studies GOLD cited examined triple therapy in a single inhaler. In the 2017 Report, possible benefits of triple therapy were discussed more generally, no longer referring specifically to newly diagnosed patients. At that time, GOLD still cautioned that more evidence was needed before firm conclusions could be drawn regarding triple therapy. In the 2019 Report, GOLD cited additional evidence from double-blind RCTs supporting benefits from triple therapy, including improved lung function, better patient-reported outcomes, and reduced risk of exacerbations. Triple therapy was added to GOLD's “Commonly Used Maintenance Medications in COPD" table in the 2019 Report.

As noted consistently in GOLD Reports to date, no single drug or combination of drugs has been shown conclusively to decrease the rate of patients' long-term decline in lung function. However, the 2020 GOLD Report cited evidence from RCTs showing that triple combinations of LABA/LAMA/ICS reduced mortality compared with a LAMA, LABA/LAMA, or LABA/ICS. Although still relatively few in number, these trials targeted patients most likely to show such an effect, namely, severely symptomatic patients with moderate to very severe airflow obstruction and a history of frequent and/or severe exacerbations; previous studies did not specifically target such patients. GOLD also noted methodological reasons to interpret the results of these studies cautiously.

Studies comparing combinations of drugs in their effects on various objective and patientreported outcomes, and especially how those effects may be modified by other factors, are few in number, limited in scope, and hence are difficult to interpret. Nonetheless, such studies are necessary steps in the refinement and personalization of treatment for COPD.

\section{INHALATION DEVICE CONSIDERATIONS}

Randomized controlled trials have not identified superiority of one device/formulation. However, patients included in these trials are usually those who master inhalation technique and receive proper education and follow-up regarding this issue, and therefore may not be reflective of normal clinical practice.

-GOLD Report, 2020

Besides the choice of inhaled drugs, key aspects influencing effectiveness of treatment are the choice of the most appropriate aerosol delivery device, proper education, device training, and adherence. Inhaled bronchodilators and ICS are typically delivered by inhalers, either pMDIs (sometimes referred to in GOLD Reports as MDIs), DPIs, or soft mist inhalers (SMIs), or by nebulizers. Each device has advantages and disadvantages. Regarding inhalers, GOLD (2017) noted that the main errors in delivery device use relate to problems with inspiratory flow, inhalation duration, coordination, dose preparation, exhalation maneuver prior to inhalation, and breath-holding following dose inhalation. Poor adherence to inhalation therapy further compounds the problem of device misuse.

GOLD has noted the importance of proper inhaler use since their first (2001) Report. In 2017, GOLD significantly expanded their discussion on inhaler use to "attempt to improve therapeutic outcomes." The 2017 and subsequent Reports more clearly emphasized that: (1) Education and training in inhaler device technique cannot be overemphasized; (2) Choice of device must be individually tailored depending on access, cost, prescriber, and most importantly, patient's ability and preference; (3) Clinicians should instruct, demonstrate, recheck, and ensure proper inhalation technique when prescribing a device, and follow up at each visit; (4) Inhaler technique and adherence should be assessed before concluding that current therapy is insufficient. This appears to mark GOLD's first distinct emphasis of the importance of choosing an appropriate inhalation device to optimize outcomes in COPD management.

GOLD's conclusions regarding regular use of nebulizers have evolved as well. In the 2001 Report, and all subsequent Reports until 2010, GOLD stated that "Nebulizers are not 
recommended for regular treatment because they are more expensive and require appropriate maintenance." In the 2006 Report, GOLD first opened the door to the possibility of recommending regular use of nebulizers in some patients by stating: "In general, nebulized therapy for a stable patient is not appropriate unless it has been shown to be better than conventional dose therapy." In 2010, GOLD no longer stated directly that nebulizers were inappropriate for patients with stable COPD, but recommendations for their use were still cautious: "Many drugs are available as nebulizer solutions and for patients who are severely overinflated and consequently may have very low inspiratory flow rates, there may be theoretical advantages of nebulizers. However, there is little randomized trial evidence for benefit compared to the use of other devices and use of nebulizers will often depend on local preference, availability and price. Benefit should be judged symptomatically, since changes in lung function may be small and within the limits of repeatability. Nebulized treatment should only be continued if the patients report clear symptomatic benefit that cannot be achieved by simpler, cheaper, and more portable alternatives." The evolution towards accepting nebulizers as a standard inhalation delivery device in patients with stable COPD continued, and the caveats noted above were removed from the GOLD Reports in 2017.

\section{CHOOSING AND MANAGING THERAPY}

In order to adjust therapy appropriately as the disease progresses, each follow-up visit should Include a discussion of the current therapeutic regimen. Monitoring should focus on: Dosages of prescribed medications; Adherence to the regimen; Inhaler technique; Effectiveness of the current regime; Side effects.

-GOLD Report, 2020

GOLD's most fundamental and consistent recommendation for managing therapy is that the choice of drug, or combination therapy, depends on the availability of the drug, its cost, and the individual response in terms of symptom relief and side effects. In 2017, GOLD revised this recommendation to include patient preference and ability to use various drug delivery devices: "Each pharmacological treatment regimen should be individualized and guided by the severity of symptoms, risk of exacerbations, side effects, comorbidities, drug availability and cost, and the patient's response, preference and ability to use various drug delivery devices."

\section{Treatment Considerations According to Drug Class}

\section{Long-Acting vs. Short-Acting Bronchodilators}

Early GOLD Reports noted that long-acting inhaled bronchodilators were more convenient than short-acting bronchodilators but were also more expensive. In 2003, for "moderate" to "very severe" disease, GOLD recommended regular treatment with long-acting bronchodilators, including tiotropium, rather than short-acting bronchodilators (Evidence A). In 2004 , it was noted more generally that longacting inhaled bronchodilators were more effective. In 2009, it was further noted that this also applied to nebulized formulations. In 2017, the Reports began to address long-acting vs. short-acting bronchodilators within specific GOLD Groups (see "A Model for Initial Pharmacological Treatment" below). In brief, either class of drug was recommended for patients with the mildest disease, whereas long-acting drugs were preferred at more advanced stages.

\section{SABA vs. SAMA}

Between 2001 and 2016, GOLD Reports stated that the bronchodilating effect of SAMAs lasts longer than that of short-acting $\beta_{2}$-agonists. The 2017 Report cited specific evidence that ipratropium, a SAMA, alone provided small benefits over SABAs in terms of lung function, health status, and requirement for oral steroids.

\section{LABA vs. LAMA}

From the 2017 Report to present, GOLD stated that LAMAs have a greater effect on exacerbation reduction compared with LABAs (Evidence A) and decrease hospitalizations 


\section{INITIAL PHARMACOLOGICAL TREATMENT}

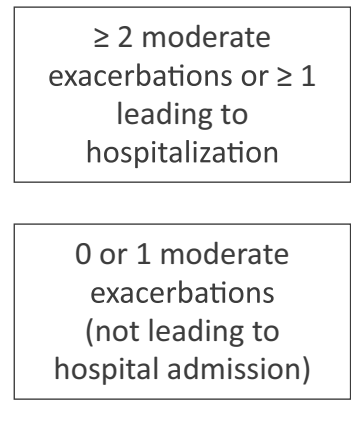

FIGURE 4.2
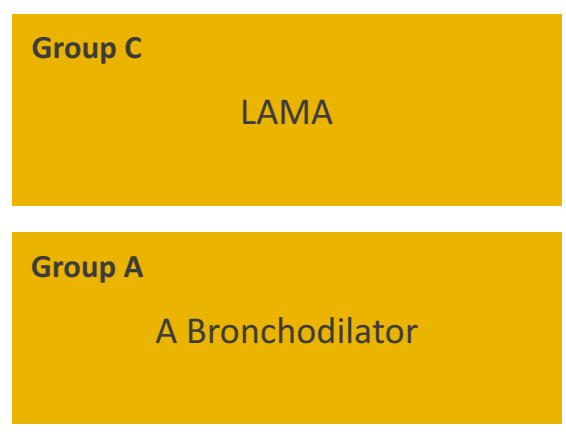

mMRC 0-1, CAT $<10$
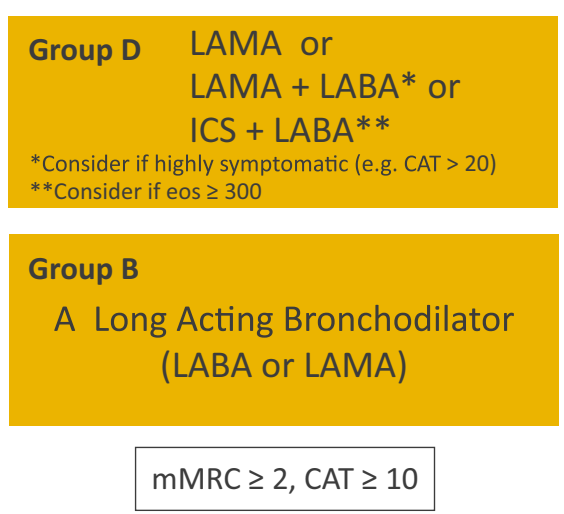

Fig. 2 A model for initial pharmacological treatment

(Evidence B). Since 2011, GOLD has also noted that a LAMA (tiotropium) may improve the effectiveness of pulmonary rehabilitation.

\section{LABA/LAMA vs. LABA/ICS}

Evidence presented in the 2019 Report suggests the possibility that the effectiveness of a LABA/ LAMA combination compared with a LABA/ICS combination depends on the presence or absence of other factors. That Report noted a study in patients with a history of exacerbations that found a combination LABA/LAMA decreased exacerbations to a greater extent than a LABA/ICS combination. Consistent with what was noted above for ICS, however, GOLD cited another study in a population with high exacerbation risk that reported that LABA/ICS decreased exacerbations to a greater extent than a LABA/LAMA combination at higher (greater than 150 cells $/ \mu \mathrm{L}$ ) blood eosinophil concentrations. Although convincing data on these associations are lacking, a history of exacerbations may favor LABA/LAMA treatment, except when eosinophil levels are high, in which case LABA/ ICS treatment may be more effective in reducing exacerbations.

\section{Triple Therapy vs. Dual or Single Therapy} Accumulating evidence cited in GOLD Reports from 2011 to 2020 supports the recent GOLD recommendations regarding triple therapy, e.g., to add a LAMA in patients already on LABA/ICS therapy who still have persistent dyspnea, exercise limitation, or exacerbations. Recommendations concerning triple therapy are problematical, however, when considering potential effect modification by exacerbation history and/or eosinophil concentrations, given: (i) sparse data from studies exploring effect modification; (ii) no known biological mechanism to explain the modifying effects; and (iii) contrasting effect modifications observed with different components of triple therapy (noted in the previous section).

\section{A Model for Initial Pharmacological Treatment}

Rescue short-acting bronchodilators should be prescribed to all patients for immediate symptom relief.

-GOLD Report, 2020

As mentioned above, in 2017, the GOLD Reports began to address recommendations for initial treatment within specific GOLD Groups (Fig. 2). For Group A patients, either short-acting or long-acting bronchodilators were recommended according to individual effectiveness and preference. For Group B patients, "Initial therapy should consist of a long-acting 


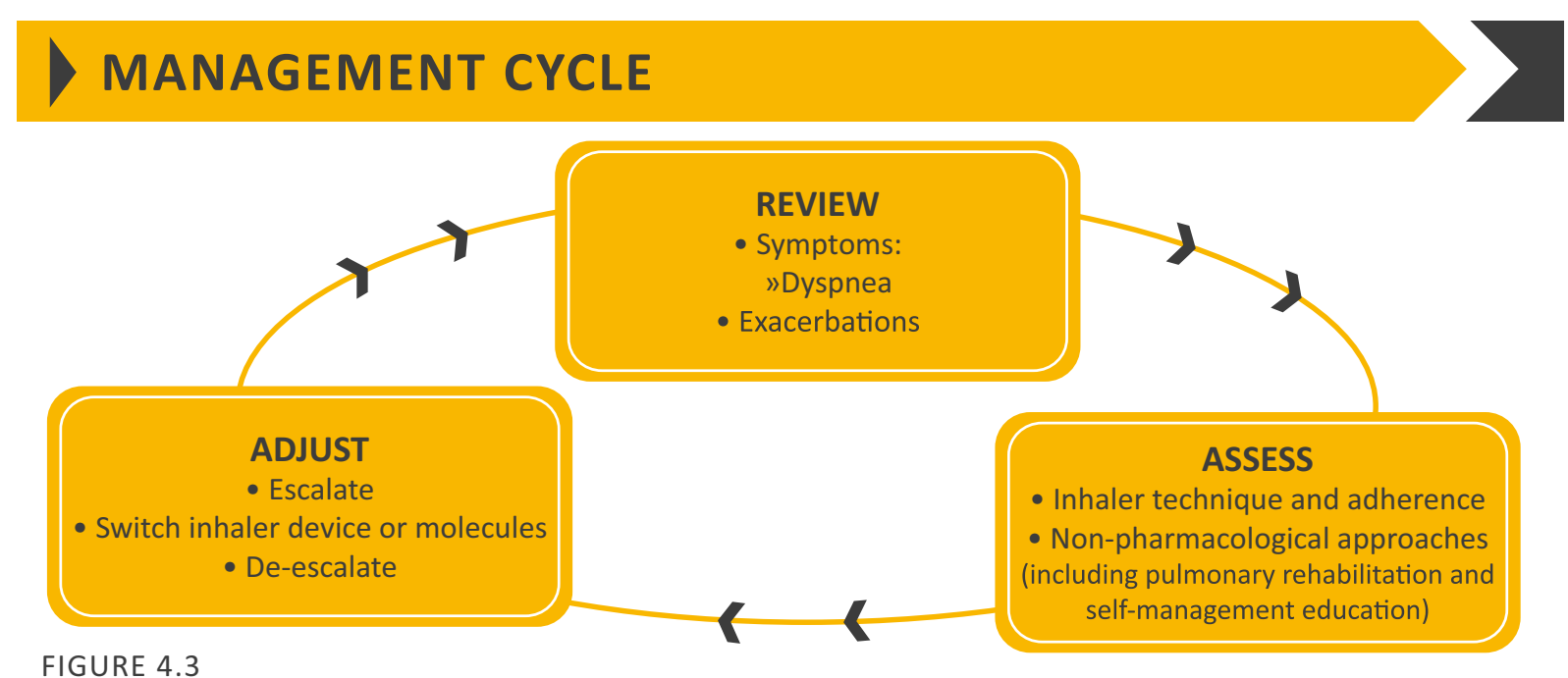

Fig. 3 A model for the reassessment of initial treatment

bronchodilator. Long-acting inhaled bronchodilators are superior to short-acting bronchodilators taken as needed." For Group C and D patients, GOLD currently recommends a longacting bronchodilator, preferably a LAMA, to prevent exacerbations. For patients with more severe symptoms, initial treatment with LAMA/ LABA may be preferable to the single drugs. In Group D, a LABA/ICS combination may be the first choice to reduce exacerbations in patients with blood eosinophil counts of at least 300 cells/ $\mu \mathrm{L}$ or a history of asthma. Because treatment goals are not always met initially, GOLD's 2019 Report further suggested a "management cycle" in which both pharmacological therapy and inhalation delivery device may be adjusted on the basis of patient symptoms and clinical events, the use of non-pharmacological approaches, and clinician assessment of inhaler technique and adherence (Fig. 3). Regarding the last of these, GOLD Reports since 2017 have noted the importance of checking inhaler technique and adherence before switching molecules.

\section{A Model for Follow-Up Pharmacological Treatment}

These follow-up recommendations are designed to facilitate management of patients taking maintenance treatment(s), whether early after initial treatment or after years of follow-up. We are fully aware that treatment escalation has not been systematically tested; trials of de-escalation are also limited and only include ICS.

-GOLD Report, 2020

Several of the recommendations for follow-up pharmacological treatment that evolved over successive Reports were noted in discussions above. These recommendations were more formally organized and presented as a model in the 2019 GOLD Report. As with initial treatment, recommendations regarding follow-up treatment are based on symptoms and exacerbations, but in this latter model they do not depend on the patient's GOLD group at initial diagnosis. Central to this model is an algorithm for changing treatments (escalation or de-escalation) when needed to improve therapeutic outcome. In brief, to improve dyspnea symptoms in patients using a single long-acting drug, a LABA/ LAMA combination may be considered. If symptoms persist, consider switching inhaler device or molecules and investigate/treat other causes of dyspnea. Symptomatic patients using a LABA/ICS combination may benefit from an added LAMA. Regarding de-escalation, patients on this triple therapy, or those taking a LABA/ICS 
combination, who are experiencing side effects, may stop taking ICS and try (or revert to) a LABA/ LAMA combination. A separate model for escalating and de-escalating treatment during exacerbations was also present in the 2019 Report.

\section{CONCLUSION}

The fundamental original idea behind GOLD is to provide a strategy for the diagnosis and the management of COPD resulting in a worldwide document and, for this reason alone, the GOLD documents cannot be regarded as a standard clinical guideline per se... GOLD has made a great contribution to capture the global COPD landscape and its very significant changes experienced over the last two decades.

-Roberto Rodriquez-Roisin, MD, Chair, GOLD Board of Directors, 2008-2011 [2].

The 20 years during which GOLD published their annual Reports has been a period of remarkable innovation and refinement of inhalation therapy for COPD. The GOLD Reports document profound evolutions in the armamentarium of inhaled drugs in all categories of inhalation devices; the use of long-acting, combination, and triple therapies; algorithms for initial and follow-up treatment; the acceptance of nebulizers in regular maintenance therapy; and the emphasis on inhalation device choice, technique, and adherence, all of which are designed to optimize outcomes in COPD management. At one time, COPD was considered to be an untreatable and progressive disease. As our analysis shows, the GOLD Reports manifest the steady, important advancements made over the last 20 years by researchers, clinicians, organizations, and COPD community members, toward a more positive and organized approach to the treatment of this widely prevalent disease.

\section{ACKNOWLEDGEMENTS}

The authors thank Ms. Katie Langefeld, Project Manager of the Global Initiative for Chronic
Obstructive Lung Disease (GOLD), and the GOLD organization, for providing access to all of the GOLD Reports.

Funding. No funding or sponsorship was received for this study or publication of this article.

Authorship. All named authors meet the International Committee of Medical Journal Editors (ICMJE) criteria for authorship for this article, take responsibility for the integrity of the work as a whole, and have given their approval for this version to be published.

Disclosures. Dr. Terry and Dr. Dhand have nothing to disclose.

Compliance with Ethics Guidelines. This article is based on previously conducted studies and does not contain any studies with human participants or animals performed by any of the authors.

Data Availability. Data sharing is not applicable to this article as no datasets were generated or analyzed during the current study.

Open Access. This article is licensed under a Creative Commons Attribution-NonCommercial 4.0 International License, which permits any non-commercial use, sharing, adaptation, distribution and reproduction in any medium or format, as long as you give appropriate credit to the original author(s) and the source, provide a link to the Creative Commons licence, and indicate if changes were made. The images or other third party material in this article are included in the article's Creative Commons licence, unless indicated otherwise in a credit line to the material. If material is not included in the article's Creative Commons licence and your intended use is not permitted by statutory regulation or exceeds the permitted use, you will need to obtain permission directly from the copyright holder. To view a copy of this licence, visit http://creativecommons.org/licenses/bync/4.0/. 


\section{REFERENCES}

1. Lenfant C. Preface to the 2001 GOLD Report. In: Pauwels RA, Buist AS, Calverley PM, Jenkins CR, Hurd SS. Global strategy for the diagnosis, management, and prevention of chronic pulmonary disease. NHLBI/WEHO Global Initiative for Chronic Obstructive Lung Disease (GOLD) Workshop summary. Am J Respir Crit Care Med 2001;163:1256-76.
2. Rodriquez-Roisin R. Twenty years of GOLD (1997-2017). The origins. https://goldcopd.org/wpcontent/uploads/2019/03/GOLD-Origins-FinalVersion-mar19.pdf. Accessed 19 Mar 2020.

3. Mirza S, Clay RD, Koslow MA, Scanlon PD. COPD guidelines: a review of the 2018 GOLD report. Mayo Clin Proc. 2018;93:1488-502. 